\title{
Synthesis, photophysical and electrochemical properties of symmetric silicon-linked coumarin-oxadiazole derivatives
}

\author{
Lingling Zhang ${ }^{\mathrm{a}}$, Yan $\mathrm{Xia}^{\mathrm{a}}$, Min $\mathrm{Li}^{\mathrm{c}}$, Dongfeng $\mathrm{Li}^{\mathrm{a},{ }^{,}}$, Ruibin $\mathrm{Hou}^{\mathrm{a}, \mathrm{b}, *}$ \\ ${ }^{a}$ School of Chemistry and Life Science, Changchun University of Technology, Changchun 130012, P. R. China \\ ${ }^{b}$ Advanced Institute of Materials Science, Changchun University of Technology, Changchun 130012, P. R.China \\ ${ }^{c}$ College of Materials Science Engineering, Jilin University, Changchun 130012, P. R.China
}

\begin{abstract}
A novel, silicon-linked, symmetric, V-shaped, coumarin derivative (1) with an electron-deficient 1,3,4-oxadiazoles unit and a phenyl moiety was synthesized and characterized. An efficient multifunctional organic light-emitting diode material was obtained through the use of optical, electrochemical, thermal, and theoretical investigations. We show that the $\mathrm{Si}$ atom induces a V-shaped structure that weakens $\pi-\pi$ stacking and thus limits aggregation-induced quenching. As expected, a gradual transition from a locally excited state to a intramolecular charge-transfer state is observed with increasing solvent polarity. This new type of compound exhibits tunable light emission in solution making it a versatile emitter.
\end{abstract}

Keywords: V-shaped, Coumarin, 1,3,4-oxadiazole, Emitter

*Corresponding authors. Tel: +86 43185716671 (R. Hou)

E-mail addresses: hrb1018@163.com (R. Hou), lidongfeng@mail.ccut.edu.cn (D. Li). 


\section{Introduction}

Luminescent organic materials have been widely used as active elements in optoelectronic devices, chemosensors, bioprobes, and organic light-emitting diodes. ${ }^{1-6}$ Most of these fluorescent organic molecules, however, exhibit planar and well-conjugated structures with reasonable emission in dilute solutions and weak or nonexistent emission in the solid state owing to aggregation-caused quenching. ${ }^{7-10}$ Recently, research has focused on reducing aggregation-induced quenching in the solid state to produce organic molecules capable of forming highly luminescent films. Multiple groups have independently reported an interesting phenomenon where in aggregated molecules are able to fluoresce more intensely than their dilute solutions. This observation has been explained in terms of the unique phenomenon of aggregation-induced emission (AIE). ${ }^{11,12}$ Propeller-shaped molecules such as tetraphenylethene, hexaphenylsilole, and quinoline-malononitrile as well as their derivatives, are known for their unique ability to promote AIE. ${ }^{13-25}$ Recently, a new V-shaped compound has displayed tunable light emission in solution and the solid state. ${ }^{26,27}$ Additionally, the integration of intramolecular charge transfer (ICT) and AIE into one compound has led to a new phenomenon: strong fluorescence not only in dilute solutions but also in the solid state or aggregated forms. For instance, Zhu and co-workers reported a new donor-acceptor system, tetraphenylethene-naphthalimide, which displayed dual photoluminescence activity from both ICT and AIE. ${ }^{5}$ However, the integration of ICT and AIE into one molecule is still rare and not well understand and thus warrants further study to understand the relationship between molecular structure and optical properties. In particular, investigations about how molecular geometry and intermolecular distances affect fluorescence are rare. This gap in the literature along with the 
above-discussed recent advances inspired us to develop a new V-shaped fluorescent molecule with tunable light emission both in solution and in the solid state.

In recent years, organosilicon compounds have become the focus of several research efforts after recent reports indicate that organosilicon compounds, especially siloles, have excellent emission properties. ${ }^{28}$ Si-based tetrahedral organic molecules and polymers have been intensively investigated as electroluminescent materials. For example, Liu and co-workers recently reported a series of tetrahedral luminescent materials comprising $\mathrm{SiAr}_{4}$ cores $^{29,30}$. They found that their fluorene derivatives were efficient blue light-emitting materials and that Si-centered materials were with good film-forming ability and quantum efficiency. One noteworthy feature of Si-centered tetrahedral materials is their high PL efficiency (nearly 100\%). ${ }^{30}$ We have recently reported a series of tetrahedral luminescent materials comprising $\mathrm{SiAr}_{2} \mathrm{Me}_{2}$ cores where the $\mathrm{Si}$ atom possesses a special V-shaped structure that exhibits tunable light emission in solution and in a solid-state thin film. ${ }^{27}$ In a continuation on our research on V-shaped luminescent materials, herein we report the development of a novel V-shaped fluorescent molecule containing coumarin-1,3,4-oxadiazole and a Si core atom. We chose coumarin as a building unit because of its well-established good luminescent properties as well as its wide application in chemosensors, light-harvesting molecular arrays, photovoltaics, and particularly in organic light-emitting diodes. ${ }^{31-34}$ Coumarin moieties' strong tendency to $\pi-\pi$ stack, however, generally leads coumarin-containing emitters to exhibit strong intermolecular interactions in the solid state, which causes aggregation-induced quenching. We found that our new V-shaped coumarin-1,3,4-oxadiazole derivative, however, does not suffer from this quenching mechanism as it exhibits strong and tunable light emission in solution and in the solid state. 

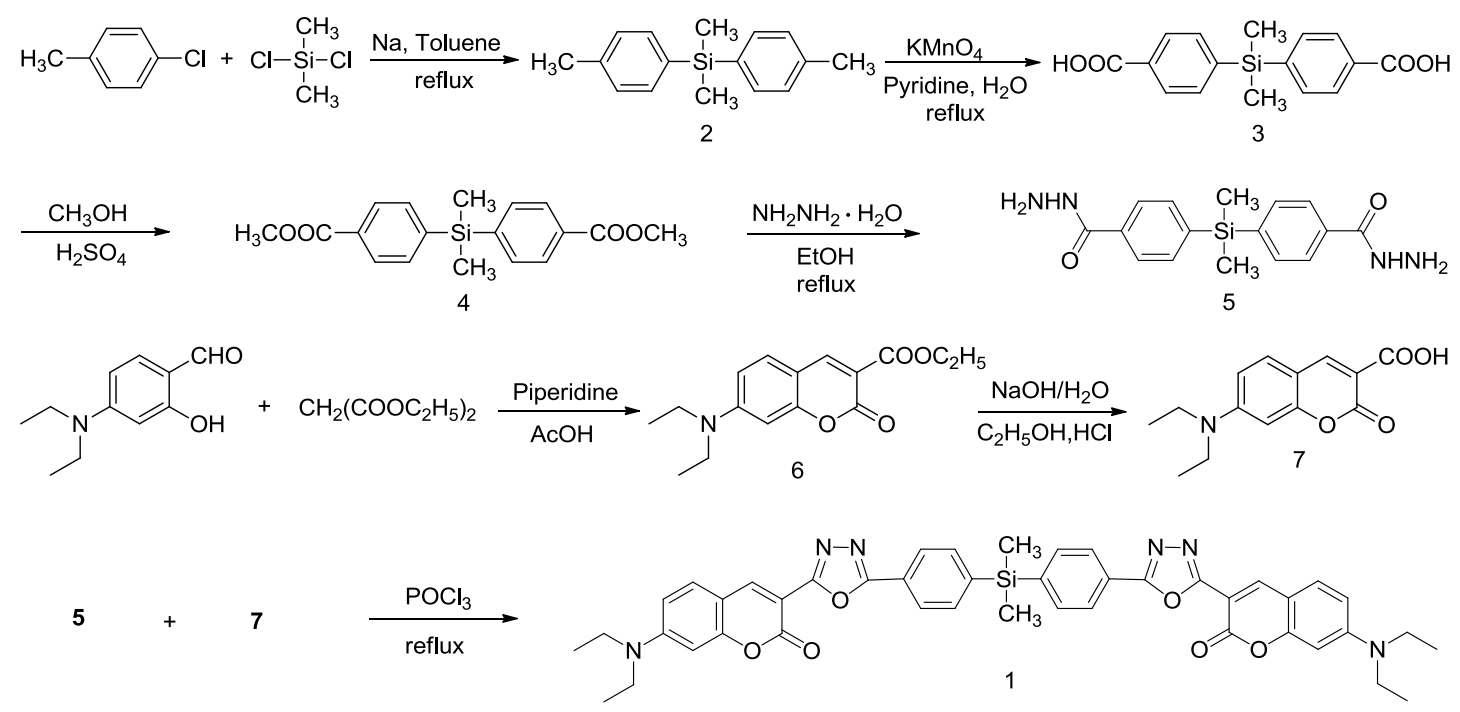

Scheme 1. Synthetic routes to the target compound 1.

\section{Results and discussion}

\subsection{Synthesis and characterization}

The synthetic procedure for target compound $\mathbf{1}$ is summarized in Scheme 1, and the detailed procedures are given in the experimental section. An important intermediate, silylbenzohydrazide moiety (5), was prepared quantitatively by the reaction of $\mathbf{4}$ with excess amounts of hydrazine monohydrate under reflux conditions. Finally the reaction of $\mathbf{5}$ and coumarin acid (7) in phosphoryl chloride as the refluxing solvent eventually produced compound $\mathbf{1}$. The structure of $\mathbf{1}$ was characterized by ${ }^{1} \mathrm{H}$ and ${ }^{13} \mathrm{C}$ NMR spectroscopy, mass spectra, and elemental analysis (see the Supporting Information).

Colourless crystals suitable for an X-ray diffraction study of the key precursor $\mathbf{5}$ was obtained by slowly evaporating $\mathrm{CH}_{2} \mathrm{Cl}_{2}$ /hexane solutions of $\mathbf{5}$ at room temperature. Its crystal structures was determined by X-ray crystallography at room temperature revealing that compound $\mathbf{5}$ crystallizes in the monoclinic system with a space group of P2/n (Table S1). As shown in Fig. 1. In the crystal structure of compound $\mathbf{5}$, the two phenyl moieties are both nearly planar and form a 
dihedral angel of $89.97( \pm 1)$. Additionally, the molecule is composed of a $\mathrm{V}$-shaped building unit separated by a silicon atom.

Crystallographic data for the structure of $\mathbf{5}$ has been deposited with the Cambridge Crystallographic Data Centre as supplemental publications CCDC 1489385 .

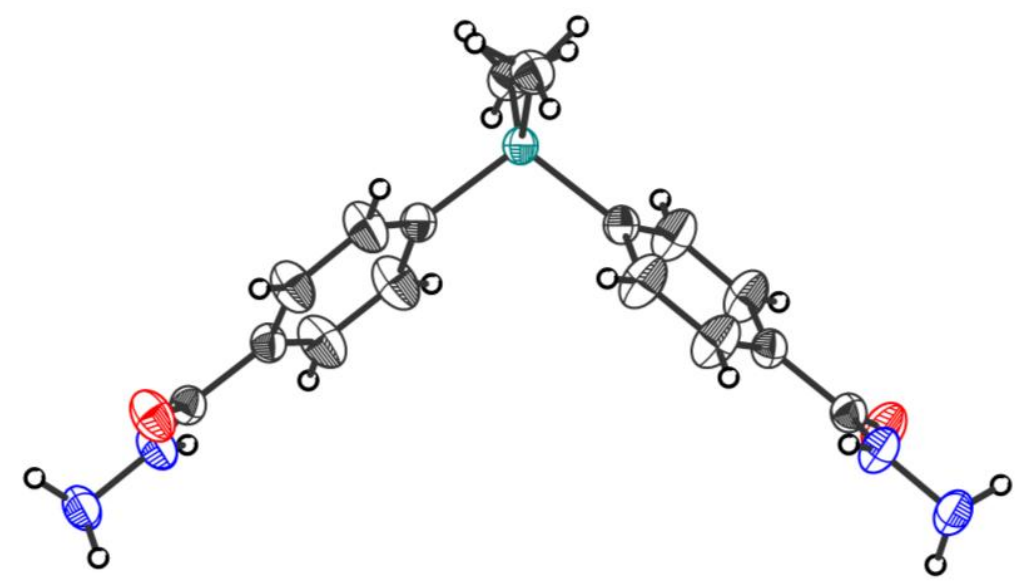

Fig. 1. Crystal structures of the key precursors 5. Thermal ellipsoids are drawn at the $30 \%$ level.

\subsection{Photophysical and electrochemical properties}

The ultraviolet-visible absorption and photoluminescence spectra of $\mathbf{1}$ in $\mathrm{CHCl}_{3}$ are displayed in Fig. 2. The three major absorption peaks located at 247, 284 and $432 \mathrm{~nm}$ originate from the $\pi-\pi^{*}$ absorption of the conjugated coumarin-phenyl 1,3,4-oxadiazole moiety. The shoulder peak at $448 \mathrm{~nm}$ can be attributed to the ICT transition character from the diethylamino to the 1,3,4-oxadiazole. The ICT transition was further confirmed by fluorescence spectra in solvents of varying polarity with the same concentration. These results are shown in Fig. 3. The emission peaks $\left(\lambda_{\mathrm{em}}\right)$ are generally red shifted from $\lambda=469 \mathrm{~nm}$ in toluene to $\lambda=496 \mathrm{~nm}$ in DMSO. The bathochromic shift, combined with the decreased quantum yield (QY), can be ascribed to stabilization of the excited state. This behavior originates from the ICT effect. ${ }^{26}$ From the absorption edge of the ultraviolet-visible spectrum, the optical band gap $\left(E_{\mathrm{g}}\right)$ of $\mathbf{1}$ is estimated to be $3.47 \mathrm{eV}$. 1 exhibits broad and structureless emission bands with peaks at $474 \mathrm{~nm}$ in $\mathrm{CHCl}_{3}$. The 
emission spectra, however, were different between the solution and film samples with regard to the broad emission peaks and red-shift shown in Fig. 2. The fluorescence QY of $\mathbf{1}$ measured at room temperature in dilute $\mathrm{CHCl}_{3}$ was moderate compared with the PL intensity of a standard solution of quinine sulfate $(\mathrm{QY}=0.54){ }^{37}$ The photoluminescence quantum efficiency of the films was measured by the integrating sphere method (Table 1).

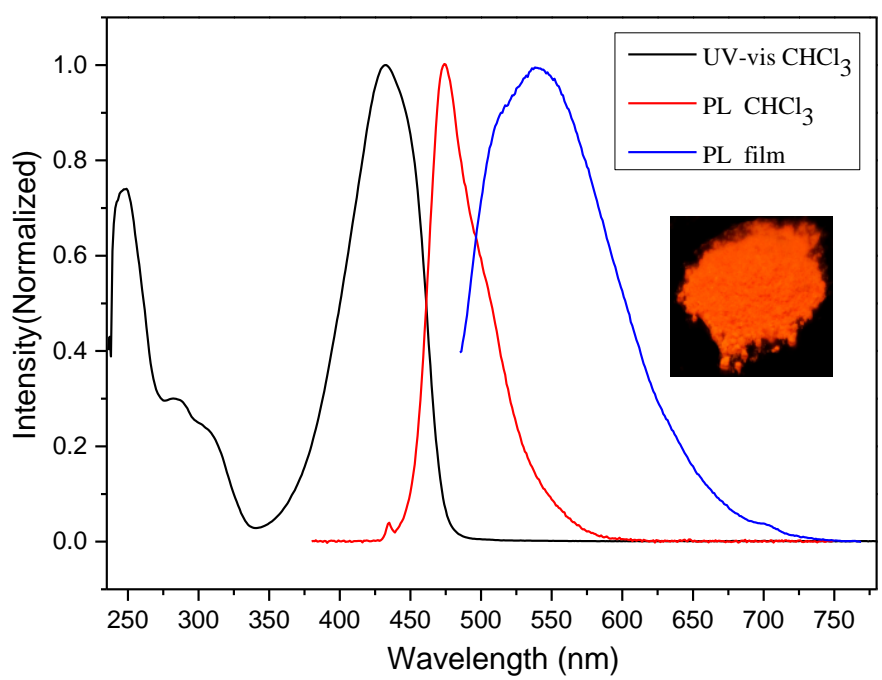

Fig. 2. UV-vis absorption and PL spectra of 1. Inset 1 Photographs of the ground powder under under $365 \mathrm{~nm}$ illumination.

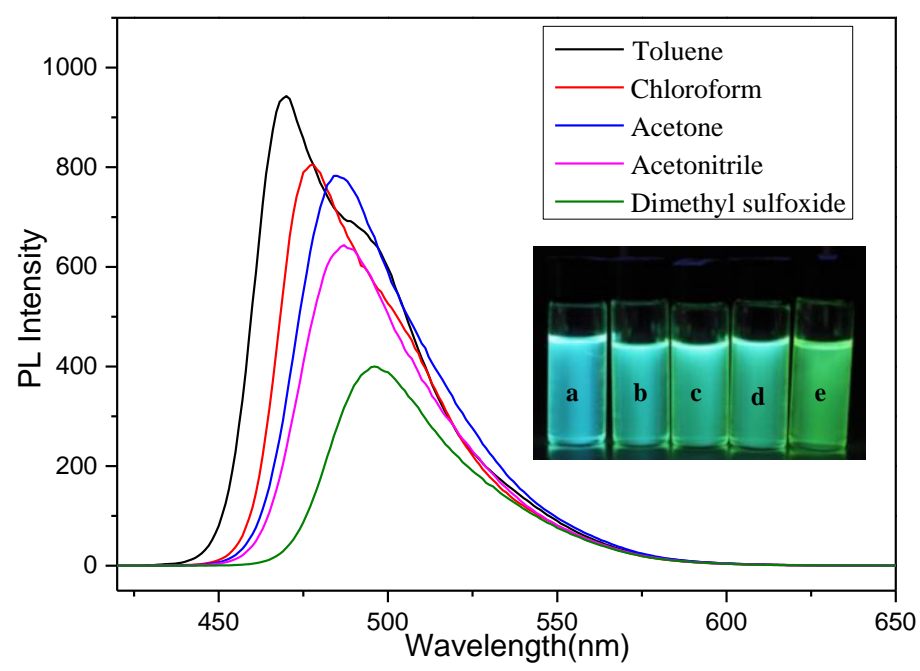

Fig. 3. PL spectra of $\mathbf{1}\left(1 \times 10^{-5} \mathrm{~mol} / \mathrm{L}\right)$ in different solvents with varying polarities. Excitation wavelength $=432 \mathrm{~nm}$. Insets show luminescence photographs of $\mathbf{1}$ in toluene(a), chloroform(b), acetone(c), acetonitrile(d), dimethyl sulfoxide (e) under $365 \mathrm{~nm}$ illumination. 
The electrochemical properties of $\mathbf{1}$ in DMF were investigated by cyclic voltammetry (CV). The electrochemical data are displayed in Table 1. Fig. 3 displays representative CV traces for the oxidation and reduction of $\mathbf{1}$ CV analyses reveal that $\mathbf{1}$ undergoes a quasi-reversible reduction at the cathodic potential associated with the reduction of the electron-deficient oxadiazole moiety to form ananion radical. 1 exhibits an irreversible oxidation processes corresponding to the removal of electrons from the terminal 7-diethylaminocoumarin group, resulting in radical cations.

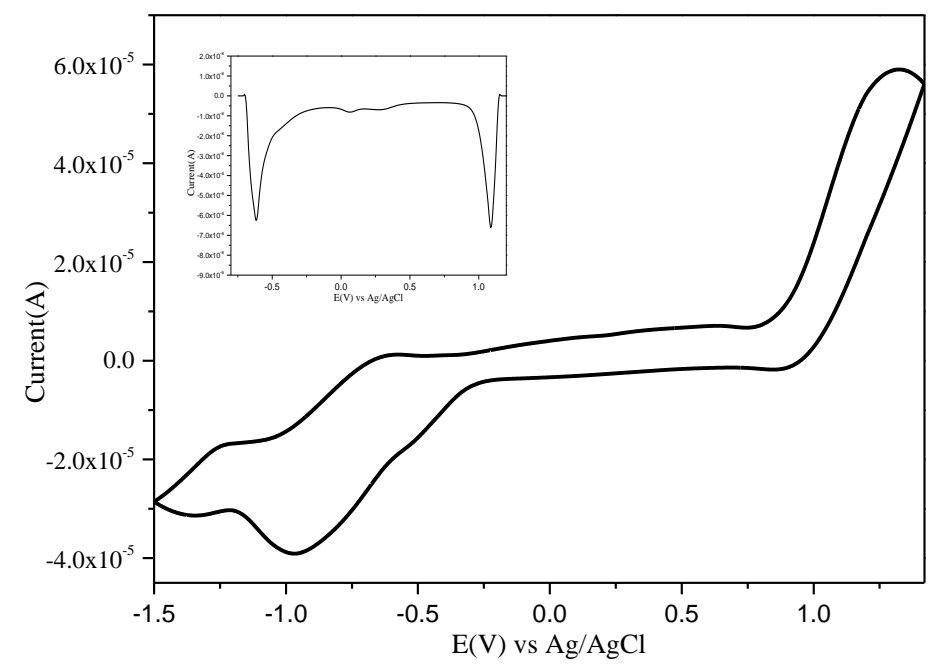

Fig. 3. Cyclic voltammograms of $\mathbf{1}$ in DMF $\left(1 \times 10^{-3} \mathrm{M}\right)$. (inset: DPV of $\mathbf{1}$ under the same conditions).

Table 1 Photophysical, physical, and electrochemical data

\begin{tabular}{ccc|c|cc|c|c|c}
\hline Compound & ${ }^{\mathrm{a}} \mathrm{A}_{\text {max }, \mathrm{Abs}}(\mathrm{nm})$ & ${ }^{\mathrm{a}} \lambda_{\max , \mathrm{em}}(\mathrm{nm})$ & ${ }^{\mathrm{b}} \lambda_{\max , \mathrm{em}}(\mathrm{n})$ & ${ }^{\mathrm{c}} \Phi_{\mathrm{F}}$ & ${ }^{\mathrm{d}} \Phi_{\mathrm{F}}$ & $\mathrm{E}^{\text {red/peak }} / \mathrm{V}$ & $\mathrm{E}_{1}{ }^{\mathrm{ox} / \text { peak }} / \mathrm{V}$ & ${ }^{\mathrm{e}} E_{g}{ }^{\text {opt }}$ \\
\hline $\mathbf{1}$ & 432.3 & 474.5 & 538.6 & 0.65 & 18.6 & -0.56 & 0.86 & 3.47 \\
\hline
\end{tabular}

${ }^{\mathrm{a}}$ Measured in $\mathrm{CHCl}_{3}$

${ }^{\mathrm{b}}$ Measured in film

${ }^{\mathrm{c}}$ Measured in $\mathrm{CHCl}_{3}$ with quinine sulfate as the standard $(\mathrm{QY}=0.54)^{37}$

${ }^{\mathrm{d}}$ The photoluminescence quantum efficiency of the films was measured by the integrating sphere method

${ }^{\mathrm{e}}$ Calculated using $E \mathrm{~g}=1240 / \lambda^{\text {abs }}{ }_{\text {onset }}$

\subsection{Thermal properties}

The thermal properties of $\mathbf{1}$ were investigated by thermal gravimetric analysis and differential scanning calorimetry under a nitrogen atmosphere. As shown in Fig. 4, the decomposition 
temperature $\left(\mathrm{T}_{\mathrm{d}}\right.$, corresponding to a weight loss of $\left.5 \%\right)$ is $398^{\circ} \mathrm{C}$. The glass transition temperature $\left(\mathrm{T}_{\mathrm{g}}\right)$ of $126{ }^{\circ} \mathrm{C}$ was also obtained from Fig. 4. The excellent thermal stability of $\mathbf{1}$ would benefit the forming of amorphous films.

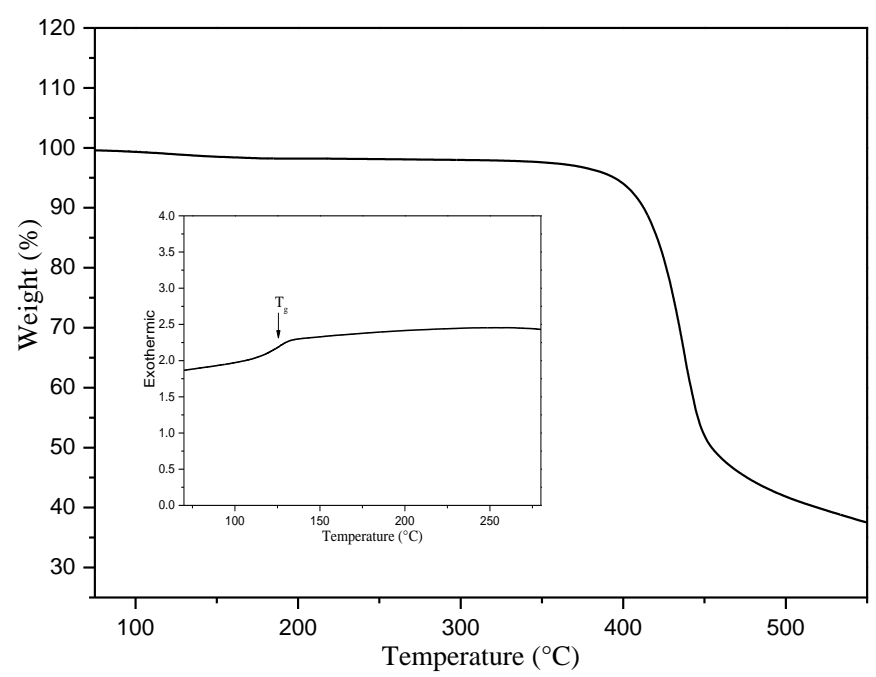

Fig. 4. Thermal gravimetric analysis traces and differential scanning calorimetry thermograms of the $\mathbf{1}$.

\subsection{Density functional theory calculations}

All calculations were carried out using the Gaussian 09 (G09) package. ${ }^{38}$ Calculations on the electronic ground state of complex 1 were carried out using density functional theory (DFT) with Becke's LYP exchange-correlation functional ${ }^{39-41}$ together with the $6-31 \mathrm{G}$ basis set. ${ }^{42}$ GaussView 5.0.8 was used for the visualization of the structures and for orbital manipulations.

To gain insight into the photophysical behavior of all of the studied complexes, DFT was used to simulate 1's molecular orbitals. To understand the charge carrier injection barriers, we investigated the changes that took place upon frontier orbital substitution. The highest occupied molecular orbital (HOMO) and the lowest unoccupied molecular orbital (LUMO) orbitals and the energy gap of $\mathbf{1}$ are displayed in Fig. 5. These results, especially the calculated energy gap $\left({ }^{\mathrm{e}} E_{g}=\right.$ $3.67 \mathrm{eV})$, largely agree with the experimental photophysical data $\left({ }^{\mathrm{e}} E_{g}{ }^{\mathrm{opt}}=3.47 \mathrm{eV}\right)$, which suggests that the DFT calculations can to a certain degree be used to predict the photophysical behavior of 
these complexes. The S1 state resulted from the HOMO $\rightarrow$ LUMO excitation (Fig. 5), which is assigned as charge transfer from the diethylamino the 1,3,4-oxadiazole moiety.

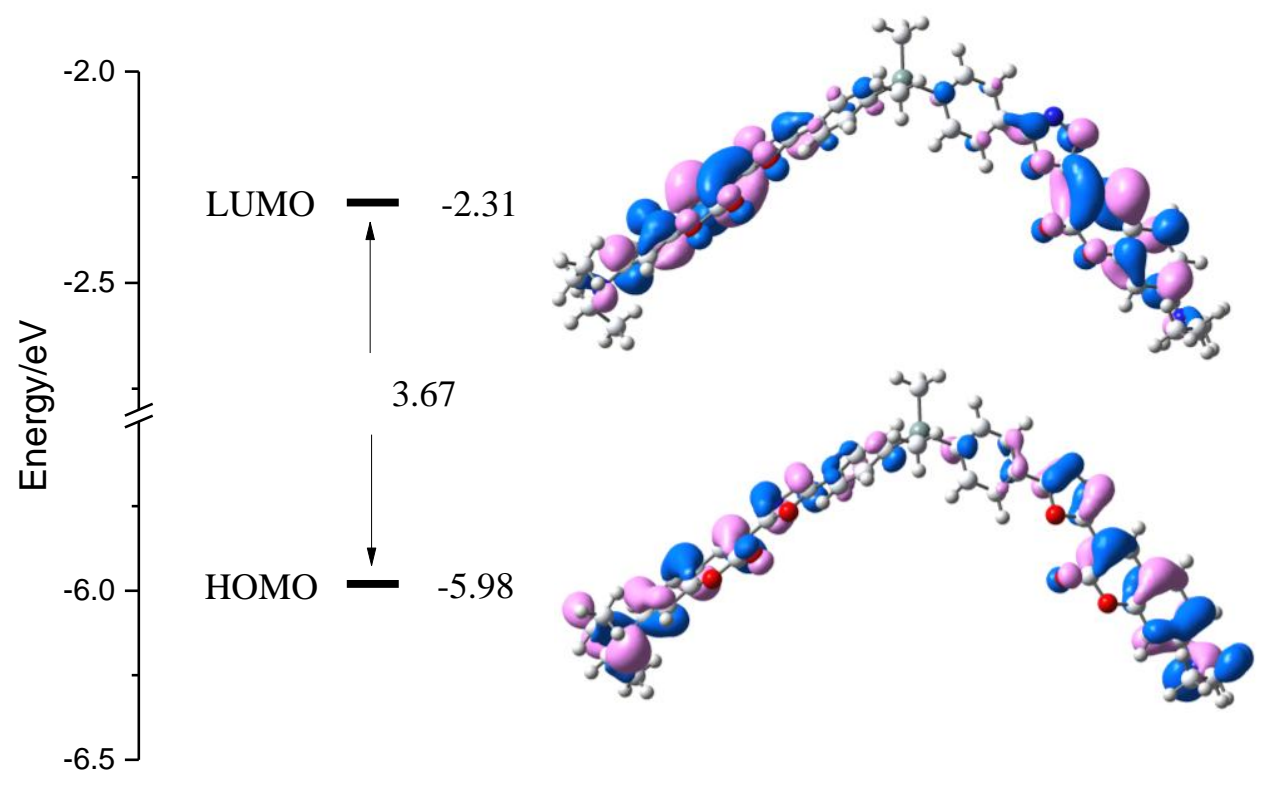

Fig. 5. Electron density contours and orbital energies calculated for the HOMO and LUMO of $\mathbf{1}$ at the Becke's LYP/DZP level in $\mathrm{CH}_{2} \mathrm{Cl}_{2}$.

The calculated vertical ionization potential $\operatorname{IP}\left(\operatorname{IP}_{v}\right)$, adiabatic IP $\left(\operatorname{IP}_{a}\right)$, vertical electron affinity $\left(\mathrm{EA}_{\mathrm{v}}\right)$, and adiabatic EA $\left(\mathrm{EA}_{\mathrm{a}}\right)$ were listed in Table 2 . The reorganization energy $(\lambda)$ can be used to estimate the charge transport rate and the balance between holes and electrons. These results were listed in Table 2. The reorganization energy for electron transport can be expressed in terms of the electron extraction potential (EEP): $\lambda_{\mathrm{e}}=\mathrm{EEP}-\mathrm{EA}_{\mathrm{v}}$. The EEP is the energy difference between $\mathrm{M}$ and $\mathrm{MM}^{-}$(anionic) when considering $\mathrm{M}^{-}$geometry. Likewise, the reorganization energy for hole transport can be expressed in terms of the hole extraction potential (HEP): $\lambda_{\mathrm{h}}=\mathrm{IP}_{\mathrm{v}}-\mathrm{HEP}$. The HEP is the energy difference between $\mathrm{M}$ and $\mathrm{MM}^{+}$(anionic) when considering $\mathrm{M}^{+}$geometry. We found that complex $\mathbf{1}$ had similar electron and hole transfer ability. Thus, $\mathbf{1}$ may be a good luminescent organic material. 
Table 2. Ionization potentials, electron affinities, extraction potentials, internal reorganization energies and $\Delta$ $=\left|\lambda_{\text {ih }}-\lambda_{\text {ie }}\right|$ (in eV) for these studied complexes.

\begin{tabular}{llllllllll|}
\hline & $\mathrm{IP}_{\mathrm{v}}$ & $\mathrm{IP}_{\mathrm{a}}$ & $\mathrm{HEP}$ & $\mathrm{EA}_{\mathrm{v}}$ & $\mathrm{EA}_{\mathrm{a}}$ & $\mathrm{EEP}$ & $\lambda_{\text {ih }}$ & $\lambda_{\text {ie }}$ & $\Delta$ \\
\hline $\mathbf{1}$ & 7.38 & 6.33 & 6.19 & 0.66 & 0.88 & 1.68 & 1.19 & 1.02 & 0.16 \\
\hline
\end{tabular}

\section{Conclusions}

We developed a facile and effective method for the synthesis of a novel, V-shaped organic fluorescent compound. A central Si atom was used to disrupt the aggregation of coumarin moieties, thus preventing aggregation-induced quenching and resulting in a QY of $18.6 \%$ in the solid state. The lack of solid-state aggregation was verified by its spectral similarities in solution and as a film. This novel emitter is solution processable and exhibits good film-forming ability and high thermal stability and could be a potential emitter.

\section{Experimental}

\section{1. General}

NMR spectra were recorded in $\mathrm{CDCl}_{3}$ with a Bruker $\mathrm{AV}-400$ Spectrometer and chemical shifts were referenced relative to tetramethylsilane $(\delta \mathrm{H} / \delta \mathrm{C}=0)$. IR spectra were recorded on a Perkin Elmer 2400 instrument (KBr pressed disc method).The mass spectra were performed on a Shimadzu MALDI AXIMA-CFRp spectrometer. Elemental analysis was performed on an Elementar Vario EL CHN elemental analyzer. Ultraviolet-visible (UV-vis) spectra were recorded on a Lambda 25 spectrophotometer in $\mathrm{CHCl}_{3}$. Fluorescence spectra were obtained from a Shimadzu RF-5301PC fluorescence spectrophotometer in $\mathrm{CHCl}_{3}$. The absolute fluorescence quantum yields ( $\Phi$ f) were measured in an integrating sphere system. Cyclic voltammetric studies were carried out using a $\mathrm{CHI} 852 \mathrm{C}$ instrument with $\mathrm{CH}_{2} \mathrm{Cl}_{2}$ as the solvent $\left(10^{-3} \mathrm{M}\right)$ and $0.1 \mathrm{M} \mathrm{Bu}_{4} \mathrm{ClO}_{4}$ as the supporting electrolyte. Counter and working electrodes 
consisted of a Pt wire and a Pt disk, respectively, and the reference electrode was $\mathrm{Ag} / \mathrm{AgCl}$. The thermal stability of the target compounds was characterized using a Shimadzu DTG-60H thermogravimetric analyzer. Starting compounds 2-7 were synthesized according to literature method. ${ }^{35,36}$

\subsection{Synthesis of}

p, p'-\{Bis[2-(7-Diethylaminocoumarinyl)-1,3,4-oxadiazol-5-yl]diphenyl\}dimethylsilane

A mixture of 7-(N,N'-diethylamino)-coumarin-3-carboxylic acid (3.86 g, $14.8 \mathrm{mmol})$, 4,4'-dihydrazidediphenyldimethylsilane $(2.43 \mathrm{~g}, 7.39 \mathrm{mmol})$ and phosphorous oxychloride $(26 \mathrm{~mL})$ was heated at reflux for $6 \mathrm{~h}$, and then poured onto crushed ice after cooling to room temperature. The dark green solid precipitate was filtered and washed thoroughly with distilled Water. After silica gel column chromatography $\left(\mathrm{EA} / \mathrm{CH}_{2} \mathrm{Cl}_{2}, 1 / 1\right.$, v/v), an orange red solid was obtained. The solid was recrystallized from THF obtained the pure final compound (2.59 g,). Yield: $45 \%$. M.p. $155.31{ }^{\circ} \mathrm{C}$ (DSC). ${ }^{1} \mathrm{H}$ NMR (400 MHz, $\left.\mathrm{CDCl}_{3}\right) \delta: 0.64$ (s, 6H), 1.25 (t, $J=7.2 \mathrm{~Hz}, 12 \mathrm{H}), 3.46(\mathrm{q}, J=7.2 \mathrm{~Hz}, 8 \mathrm{H}), 6.53(\mathrm{~d}, J=2.4 \mathrm{~Hz}, 2 \mathrm{H}), 6.65(\mathrm{dd}, J=8.8 \mathrm{~Hz}, 2 \mathrm{H})$, $7.41(\mathrm{~d}, J=8.8 \mathrm{~Hz}, 2 \mathrm{H}), 7.67(\mathrm{~d}, J=8.0 \mathrm{~Hz}, 4 \mathrm{H}), 8.15(\mathrm{~d}, J=8.0 \mathrm{~Hz}, 4 \mathrm{H}), 8.51(\mathrm{~s}, 2 \mathrm{H}),{ }^{13} \mathrm{C} \mathrm{NMR}$ $\left(100 \mathrm{MHz}, \mathrm{CDCl}_{3}\right) \delta:-2.59,12.54,45.20,97.09,103.77,107.98,109.92,124.74,126.32,130.73$, 134.75, 142.22, 144.90, 152.71, 157.70, 157.92, 162.24, 164.63; FT-IR $\left(\mathrm{KBr}, \mathrm{cm}^{-1}\right): 2972,2918$, $1733,1623,1596,1533,1415,1228,814 ; \mathrm{C}_{44} \mathrm{H}_{42} \mathrm{~N}_{6} \mathrm{O}_{6}$ Si calculated for $[\mathrm{M}+\mathrm{H}]^{+} 778.94$, found 779.33 .

\section{Acknowledgements}

This work was supported by the National Science Foundation of China (No. 21442004), The education office of Jilin provincial (grant No. 2016320). 


\section{References}

1.Tang, C. W. Vanslyke, S. A. Appl. Phys. Lett. 1987, 51, 913.

2. Xu, C . Li, H . Kan, Y . Yin, B. Biosensors and Bioelectronics 2015, 72 , 275.

3. Lamansky, S. Djurovich, P. Murphy, D. Abdel-Razzaq, F. Lee, H. E. Adachi, C.

Buttows, P. E. Forrest, S. R. Thompson, M. E. J. Am. Chem. Soc. 2001, 123, 4304.

4. Yang, Y. Zhao, Q. Feng, W. Li, F. Chem. Rev. 2013, 113, 192.

5. Feng, X. Tian, P. Xu, Z. Chen, S. Wong, M.J. Org. Chem. 2013,78, 11318.

6. Scherf, U. List, E. AdV. Mater. 2002,14, 477.

7. Birks, J. B. Photophysics of Aromatic Molecules; Wiley: London, U.K., 1970.

8. Mancin, F. Scrimin, P. Tecilla, P. Tonellato, U. Coord. Chem. Rev. 2009, 253, 2150.

9. Thomas, S. W. Joly, G. D. Swager, T. M. Chem. Rev. 2007,107, 1339.

10. Chen, C. T. Chem. Mater. 2004,16, 4389.

11. Hong, Y. Lam, J. W. Y. Tang, B. Z. Chem. Soc. Rev. 2011, 40 , 5361.

12. Yuan, W. Z. Zhao, H. Shen, X. Y. Mahtab, F. Lam, J. W. Y. Sun, J. Z. Tang, B. Z. Macromolecules, 2009, 42, 9400 .

13. Yu, G. Yin, S. Liu, Y. Chen, J. Xu, X. Sun, X. Ma, D. Zhan, X. Peng, Q. Shuai, Z. Tang, B. Z. Zhu, D. Fang, W. Luo, Y. J. Am. Chem. Soc. 2005, 127, 6335.

14. Zhang, T. Jiang, Y. Niu, Y. Wang, D. Peng, Q. Shuai, Z. J. Phys. Chem. A. 2014,118, 9094.

15. Zhang, X. Ma, Z. Yang, Y. Zhang, X. Jia, X. Wei, Y. J. Mater. Chem. C. 2014, $2,8932$.

16. Simalou, O. Lu, R. Xue, P. Gong, P. Zhang, T. Eur. J. Org. Chem. 2014,14, 2907.

17. Wang, J.H. Feng, H.T. Luo, J. Zheng, Y. S. J. Org. Chem. 2014, 79, 5746.

18. Upamali, K. A. N. Estrada, L. A. De, P. K. Cai, X. Krause, J. A. Neckers, D. C. 
Langmuir, 2011, 27, 1573.

19. Li, H. Zhang, X. Chi, Z. Xu, B. Zhou, W. Liu, S. Zhang, Y. Xu, J. Org. Lett. 2011,13, 556.

20 H. Tong, Y. Dong, Y. Hong, M. Häußler, J. W. Y. Lam, H. H. Y. Sung, X. Yu, J. Sun, I. D. Williams, H. S. Kwok, B. Z. Tang, J. Phys. Chem. C. 111( 5) (2007) 2287.

21. Liu, G. Chen, D. Kong, L. Shi, J. Tong, B. Zhi, J. Feng, X. Dong, Y. Chem. Commun. 2015, 51, 8555.

22. Shiraishi, K. Kashiwabara, T. Sanji, T. Tanaka, M. New J. Chem. 2009, 33, 1680.

23. Chen, M. Li, L. Nie, H. Tong, J. Yan, L. Xu, B. Sun, J. Z. Tian, W. Zhao, Z. Qin, A.

Tang, B. Z. Chem. Sci. 2015, 6, 1932.

24. Zhang, R. Gao, M. Bai, S. Liu, B. J. Mater. Chem. B. 2015, 3, 1590.

25. Fu, Y. Qiu, F. Zhang, F. Mai, Y. Wang, Y. Fu, S. Tang, R. Zhuang, X. Feng, X. Chem. Commun. $\mathbf{2 0 1 5}, 51,5298$.

26. Gu, P. Zhang, Y. Liu, G. Ge, J. Xu, Q. Zhang, Q. Lu. J. Chem. Asian J. 2013, 8, 2161.

27. Li, D. Huang, Z. Shang, X. Xia, Y. Zhang, Y. Li, M. Li, B. Hou, R. Tetrahedron, 2015, 71, 2680.

28. Zhao, Z. He, B. Tang, B. Z. Chem. Sci. 2015, 6, 5347.

29.Liu, X. M. He, C. Hao, X. T. Tan, L. W. Li, Y. Ong. K. S. Macromolecules, 2004, 37, 5965.

30. Liu, X. M. He, C. Huang, J. Xu, J. Chem. Mater. 2005, 17, 434.

31. Zhou, X. Jin, X. Sun, G. Li, D. Wu, X. Chem. Commun. 2012, 48, 8793.

32. Scott, T. Allan, R. S. Brian, R. L. Timothy, E. J. L. Chem. Rev. 2004, 104, 3059.

33. Yu, T. Zhang, P. Zhao, Y. Zhang, H. Meng, J. Fan, D. Organic Electronics, 2009, 10, 653.

34. Zhang, H. Yu, T. Zhao, Y. Fan, D.Xia, Y. Zhang, P. Synthetic Metals, $2010,160,1642$. 
35 Tang, H. Song, N. Gao, Z. Chen, X. Fan, X. Xiang, Q. Zhou. Q. Polymer, 2007, 48, 129.

36. Zhang, H. Yu, T. Zhao, Y. Fan, D. Chen, L. Qiu, Y. Qian, L. Zhang, K. Yang, C. Spectrochim. Acta Part A: Mol. Biomol. Spectrosc, 2008, 69, 1136.

37. Kartens, T. Kobs. K. J. Phys. Chem. 1980, 84,1871.

38. Frisch, M. J. Trucks, G. W. Schlegel, H. B. Scuseria, G. E. Robb, M. A. Cheeseman, J. R.

Scalmani, G. Barone, V. Mennucci, B. Petersson, G. A. Nakatsuji, H. Caricato, M. Li, X.

Hratchian, H. P. Izmaylov, A. F. Bloino, J. Zheng, G. Sonnenberg, J. L. Hada, M. Ehara, M.

Toyota, K. Fukuda, R. Hasegawa, J. Ishida, M. Nakajima, T. Honda, Y. Kitao, O. Nakai, H.

Vreven, T. Montgomery, J. A. Peralta, Jr. J. E. Ogliaro, F. Bearpark, M. Heyd, J. J. Brothers, E.

Kudin, K. N. Staroverov, V. N. Keith, T. Kobayashi, R. Normand, J. Raghavachari, K. Rendell,

A. Burant, J. C. Iyengar, S. S. Tomasi, J. Cossi, M. N. Rega, Millam, J. M. Klene, M. Knox, J.

E. Cross, J. B. Bakken, V. Adamo, C. Jaramillo, J. Gomperts, R. Stratmann, R. E. Yazyev, O.

Austin, A. J. Cammi, R. Pomelli, C. Ochterski, J. W. Martin, R. L. Morokuma, K. Zakrzewski,

V. G. Voth, G. A. Salvador, P. Dannenberg, J. J. Dapprich, S. Daniels, A. D. Farkas, O.

Foresman, J. B. Ortiz, J. V. Cioslowski J. Fox, D. J. GAUSSIAN 09 (Revision B.01). Gaussian,

Inc., Wallingford CT, 2010.

39. Hohenberg, P. Kohn, W. Physical Review, 1964, 136, 864.

40. Lee, C. Yang, W. T. Parr, R. G. Physical Review B,1988, 37, 785.

41. Becke, A. D. Journal of Chemical Physics. 1993, 98, 5648.

42. Hariharan, C. Pople, J. A. Molecular Physics, 1974, 27, 209. 